\title{
A Hybrid Risk Evaluation Model for Automotive Production
}

\author{
Mehmet Turgut and Alp Ustundag, Member, IACSIT
}

\begin{abstract}
Failure mode and effects analysis (FMEA) is used commonly for the prioritization of failures in the automotive production. Traditional FMEA determines the risk priorities of failure modes, which require the risk factors like the occurrence $(\mathrm{O})$, severity (S) and detection (D) of each failure mode to be evaluated. However, it has some drawbacks so that affect the risk evaluation and correction action. It is very difficult for three risk factors to be evaluated precisely. Additionally, traditional method cannot capture different team members' opinions and prioritize failure modes under different types of uncertainties. So, in this study, FMEA using fuzzy evidential approach and grey theory are used to prioritize the failures for a truck production company in Turkey. Degrees of relation for the six failure modes are determined. The defect of "unstable" is found as the most important and serious risk according to the analysis.
\end{abstract}

Index Terms-Automotive production, failure mode and effects analysis (FMEA), fuzzy evidential approach, grey theory, risk prioritization.

\section{INTRODUCTION}

Automotive industry is one of the largest industries in the world which is mostly invested and has billion dollars turnover. Approximately, fifty manufacturer companies operate in 20 countries in the world. China is in the first place of vehicles production in the world since 2009 which is followed by United States of America and Japan. However, Turkey is the 17 th country in the automotive production in the world in 2011 [1].

Automotive industry of Turkey has experienced four main stages from past to present. Between the years of 1960 and 1980 , the market was import-oriented and under protection. In 1981, a transformation process focusing on export-oriented production has begun and lasted until 1995. In the third stage, free market and perfect competition conditions were met as of 2004. In the final stage, since 2005, automotive companies in Turkey have focused on $R \& D$, design and technology management [2], [3].

Production is very wide and detailed process in automotive industry which brings many serious risks. So, risk should be managed accurately and carefully. When we mention about the risk management, we think about the ability to define what may happen in the future, assess associated risks and uncertainties and to choose among alternatives [4]. There are three kinds of risks in the literature, namely financial, operational and legal [5]. Operational risks are considered as

Manuscript received March 2, 2014; revised May 10, 2014.

The authors are with the Istanbul Technical University, Industrial Engineering Department Macka 34367 Istanbul, Turkey (e-mail: turgutmeh@itu.edu.tr, ustundaga@itu.edu.tr). negative events such as an incomplete, false process or human error which are a result of an activity of an organization [6]. In this paper, operational risks in automotive production are handled.

Risk management is a process that controls, evaluates and defines the risks before occurring in operational activities [7] A typical process of risk management contains four basic steps [8]. The first step is the risk identification which helps understanding the future uncertainties across the supply chain, thus identifying the potential risks. The second step is the risk assessment, which refers to quantification of the risks and identifying the consequences of them. As a third step, risk management actions are to be implemented including the backup scenarios and risk mitigation actions. And finally the fourth step is the risk monitoring where the system is supervised to detect the risks when they occur.

Failure mode and effects analysis (FMEA) is a systematic approach in the risk management which is used for prioritization, elimination and determination of possible failures of products and processes.

Traditional FMEA determines the risk priorities of failure modes, which require the risk factors like the occurrence $(\mathrm{O})$, severity (S) and detection (D) of each failure mode to be evaluated. However, it has some drawbacks so that affect the risk evaluation and correction action. It is very difficult for three risk factors to be evaluated precisely. Also, traditional method cannot capture different team members' opinions. There are different types of FMEA approaches in the literature such as multi-criteria decision making (MCDM), mathematical programming, artificial intelligence, hybrid approaches and others [9]. FMEA using fuzzy evidential reasoning approach and grey theory overcome the mentioned drawbacks of the traditional method [10]. Hence, in this study, this hybrid method is used for prioritization of risks in production processes of a truck company in Turkey. The rest of the paper is organized as follows: The method of FMEA using fuzzy evidential reasoning approach and grey theory is explained in Section II. Section III presents the risk evaluation of automotive production in an application. Finally, conclusions are provided in Section IV.

\section{FMEA USING FUZZY EVIDENTIAL REASONING APPROACH AND GREY THEORY}

\section{A. Fuzzy Evidential Reasoning Approach}

Fuzzy evidential reasoning approach was first developed in 1994 for dealing with multiple attribute decision analysis problems which include both quantitative and qualitative attributes with various types of uncertainties. In this method, risk factors are assessed using belief structures and individual belief structures are synthesized into group belief structures. 
Then, defuzzified group belief structures are aggregated into overall belief structure [10]. The decisions of team members in FMEA can't be certain all the time. That's why, a structure is needed that can also evaluate the incomplete, uncertain decisions, so team members decide with belief structures in fuzzy evidential approach. Fuzzy evidential approach using belief structures provides more flexible and easier usage compared to traditional method. Belief structures are an assessment of ideas and they are mostly used in multi-criteria decision making. They represent alternative options on a criterion [11].

In this approach, risk factors are measured better than the traditional method. Assessments of risk factors are done with degrees on fuzzy sets as follows:

$$
\begin{aligned}
& H_{F}=\left\{H_{11}, H_{22}, H_{33}, H_{44}, H_{55}\right\}= \\
& \text { \{Very low, Low, Moderate, High, Very high }\}
\end{aligned}
$$

Fuzzy graduation is made for linguistic terms according to Table I. Fuzzy logic approach brings an improvement to traditional method which is a possibility of evaluation between two degrees. Lastly, it enables not to evaluate a failure mode for a team member if the team member is indecisive or not willing to decide

Group belief structures: In an FMEA team, it is assumed that there are $L$ risk factors $\left(R F_{1} \ldots R F_{L}\right), N$ failure modes $\left(F M \ldots F M_{N}\right)$ and $K$ team members $\left(T M_{1} \ldots T M_{K}\right)$. Each team member has its own relative weight. Relative weights of risk factors are expressed as $\widetilde{w}_{l}^{k}=\left(w_{l a}^{k}, w_{l b}^{k}, w_{l d}^{k}\right)$. Degrees are determined according to fuzzy linguistic terms in Table II.

TABLE I: FUZZY GRADUATION FOR LINGUISTIC TERMS

\begin{tabular}{lc}
\hline \hline Linguistic terms & Fuzzy numbers \\
\hline Very low & $(0,0,1,2)$ \\
Low & $(1,2,3,4)$ \\
Moderate & $(3,4,6,7)$ \\
High & $(6,7,8,9)$ \\
Very high & $(8,9,10,10)$ \\
\hline \hline
\end{tabular}

TABLE II: EXPRESSIONS OF FUZZY WEIGHTS FOR THE RELATIVE IMPORTANCE OF RISK FACTORS

\begin{tabular}{lc}
\hline \hline Linguistic terms & Fuzzy numbers \\
\hline Very low & $(0,0,0.25)$ \\
Low & $(0,0.25,0.5)$ \\
Moderate & $(0.25,0.5,0.75)$ \\
High & $(0.5,0.75,1)$ \\
Very high & $(0.75,1,1)$ \\
\hline \hline
\end{tabular}

Relative weights of risk factors are calculated in (1).

$$
\begin{gathered}
\widetilde{W_{l}}= \\
\sum_{k=1}^{K} \lambda_{k} \widetilde{w}_{l}^{k}=\left(\sum_{k=1}^{K} \lambda_{k} w_{l a}^{k}, \sum_{k=1}^{K} \lambda_{k} w_{l b}^{k}, \sum_{k=1}^{K} \lambda_{k} w_{l d}^{k}\right) \\
l=1 \ldots . L
\end{gathered}
$$

Equation (7) is used for the defuzzification of group weights of risk factors then these values are normalized in (2).

$$
\widetilde{w_{l}}=\frac{w_{l}}{\sum_{l=1}^{L} w_{l}} \quad l=1, \ldots ., L
$$

$\beta_{i j}^{k}\left(F M_{n}, R F_{l}\right)$ is called belief degree. So, all degrees and intervals are expressed as in (3).

$$
\widehat{H}_{F}=\left\{H_{i j}, i=1, \ldots, 5 ; j=1, \ldots, 5\right\}
$$

For each failure mode, collective assessment of team members regarding to each risk factor is called group belief structure, which is given in (4).

$$
\tilde{X}_{n}(l)=\left\{\left(H_{i j}, \beta_{i j}^{k}\left(F M_{n}, R F_{l}\right)\right), i=1, \ldots . .5 ; j=1, \ldots . .5\right\}
$$

$$
n=1 \ldots \ldots N ; \quad l=1 \ldots . L
$$

$\beta_{i j}^{k}\left(F M_{n}, R F_{l}\right)$ is group belief degree and calculated in (5).

$$
\begin{gathered}
\beta_{i j}^{k}\left(F M_{n}, R F_{l}\right)=\sum_{k=1}^{K} \lambda_{k} \beta_{i j}^{k}\left(F M_{n}, R F_{l}\right) \\
i=1 \ldots \ldots 5 ; \quad j=1 \ldots .5 \\
n=1 \ldots \ldots N ; \quad l=1 \ldots . . L
\end{gathered}
$$

The group belief structure for $N$ failure modes regarding to the $L$ risk factors constitute fuzzy belief decision matrix in (6).

$$
\tilde{X}=\left[\begin{array}{c}
F M_{1} \\
F M_{2} \\
\vdots \\
\vdots \\
F M_{N}
\end{array}\right]=\left[\begin{array}{cccc}
\tilde{X}_{1}(1) & \tilde{X}_{1}(2) & \ldots & \tilde{X}_{1}(L) \\
\tilde{X}_{2}(1) & \tilde{X}_{2}(2) & \ldots & \tilde{X}_{2}(L) \\
\vdots & \vdots & \ldots & \vdots \\
\vdots & \vdots & \cdots & \vdots \\
\tilde{X}_{N}(1) & \tilde{X}_{N}(2) & \cdots & \tilde{X}_{N}(L)
\end{array}\right]
$$

Defuzzification: Defuzification and weighted average method are used to transform the group belief structures into a general belief structure using (7). Membership functions of fuzzy trapezoid diagram are used for defuzzification of group weights of risk factors.

$$
\begin{aligned}
h_{i j} & =\frac{\sum_{i=0}^{n}(b i-c)}{\sum_{i=0}^{n}(b i-c)-\sum_{i=0}^{n}(a i-d)} \\
& i=1 \ldots \ldots 5 ; \quad j=1 \ldots .5
\end{aligned}
$$

Finally general belief structure is obtained using (8) where $h_{i j}$ is defuzzified crisp number of $H_{i j}$. It is also shown in the matrix form in (9).

$$
\begin{gathered}
X_{n}(l)=\sum_{i=1}^{5} \sum_{j=1}^{5} h_{i j} \beta_{i j}\left(F M_{n}, R F_{l}\right) \\
n=1 \ldots \ldots N ; \quad l=1 \ldots \ldots L \\
X=\left[\begin{array}{c}
F M_{1} \\
F M_{2} \\
\vdots \\
\vdots \\
F M_{N}
\end{array}\right]=\left[\begin{array}{cccc}
X_{1}(1) & X_{1}(2) & \ldots & X_{1}(L) \\
X_{2}(1) & X_{2}(2) & \ldots & X_{2}(L) \\
\vdots & \vdots & \ldots & \vdots \\
\vdots & \vdots & \cdots & \vdots \\
X_{N}(1) & X_{N}(2) & \cdots & X_{N}(L)
\end{array}\right]
\end{gathered}
$$

\section{B. Grey Theory}

Grey theory, proposed by Deng in 1989 deals with decisions characterized by incomplete information which are partially known [12]. It constructs model and uses relation analysis to explore system behavior. In grey theory, comparative series and standard series are established then; the difference between comparative series and standard series is obtained. In addition, grey relational coefficient is 
computed with these values and finally, degree of relation is computed to rank the failure modes. The smaller the risk priority of failure modes are, the higher the grey relational degrees and risks are prioritized [10].

Comparative series: These series have $L$ risk factors and expressed as $X_{n}^{\prime}=\left(X_{n}^{\prime}(1) X_{n}^{\prime}(2), \ldots, X_{n}^{\prime}(L)\right) \in X^{\prime}$, where $X_{n}^{\prime}(l), \quad l=1, \ldots, L$ denotes the factors of $X_{n}^{\prime} . N$ series are obtained from (10).

$$
X^{\prime}=\left[\begin{array}{c}
X_{1}^{\prime} \\
X_{2}^{\prime} \\
\vdots \\
\vdots \\
X_{N}^{\prime}
\end{array}\right]=\left[\begin{array}{cccc}
X_{1}^{\prime}(1) & X_{1}^{\prime}(2) & \ldots & X_{1}^{\prime}(L) \\
X_{2}^{\prime}(1) & X_{2}^{\prime}(2) & \ldots & X_{2}^{\prime}(L) \\
\vdots & \vdots & \cdots & \vdots \\
\vdots & \vdots & \cdots & \vdots \\
X_{N}^{\prime}(1) & X_{N}^{\prime}(2) & \cdots & X_{N}^{\prime}(L)
\end{array}\right]
$$

Standard series are expressed as $X_{0}=\left[X_{0}(1), X_{0}(2), \ldots, X_{0}(L)\right]$ and they are determined as the lowest level of risk factors.

$$
\begin{gathered}
X_{0}=\left[X_{0}(1), X_{0}(2), \ldots, X_{0}(L)\right]=\left[H_{11}, H_{11}, \ldots, H_{11}\right] \\
=\left[h_{11}, h_{11}, \ldots, h_{11}\right]
\end{gathered}
$$

Difference between comparative and standard series: It is computed as $\Delta_{0 n}(l)=\left\|X_{0}(l)-X_{n}(l)\right\|$ where $X_{0}(l)$ and $X_{n}(l)$ denote standard and comparative series respectively. They are expressed as a matrix in (12)

$$
D_{0}=\left[\begin{array}{cccc}
\Delta_{01}(1) & \Delta_{01}(2) & \ldots & \Delta_{01}(L) \\
\Delta_{02}(1) & \Delta_{02}(2) & \ldots & \Delta_{02}(L) \\
\vdots & \vdots & \ldots & \vdots \\
\vdots & \vdots & \cdots & \vdots \\
\Delta_{0 N}(1) & \Delta_{0 N}(2) & \cdots & \Delta_{0 N}(L)
\end{array}\right]
$$

Grey relational coefficient: It is expressed as $\gamma\left(X_{0}(l), X_{n}(l)\right)$ for each risk factor of failure and computed as in (13)

$$
\begin{aligned}
& \gamma\left(X_{0}(l), X_{n}(l)\right)= \\
& \frac{\min _{n} \min _{l}\left|X_{0}(1)-X_{n}(1)\right|+\zeta \max _{n} \max _{l}\left|X_{0}(1)-X_{n}(1)\right|}{\left|X_{0}(1)-X_{n}(1)\right|+\zeta \max _{n} \max _{l}\left|X_{0}(1)-X_{n}(1)\right|} \\
& =\frac{\Delta_{\min }+\zeta \Delta_{\max }}{\Delta_{0 n}(l)+\zeta \Delta_{\max }} \\
& \quad n=1 \ldots \ldots N ; \quad l=1 \ldots . . L
\end{aligned}
$$

where $X_{0}(l)$ and $X_{n}(l)$ are the minimum and maximum values of standard and comparative series respectively. Also, $\zeta$ is a decisive number and taken generally 0.5 where $\zeta$ $\in(0,1)$.

The degree of relation: It is computed by using group weights of risk factors and grey relational coefficient using (14). Failure modes are ranked according to the computed values.

$$
\Gamma\left(X_{m}, X_{n}\right)=\sum_{l=1}^{L} \bar{w}_{l} \gamma\left\{X_{m}(l), X_{n}(l)\right\}
$$

\section{APPLICATION}

In this section, six defects encountered mostly in the automotive industry are prioritized with FMEA using fuzzy evidential approach and grey theory. The application is conducted in a truck production company of Turkey where the defects are determined as scrubbing, unstable, false assembly, weak painting, scratch and welding splash. Three risk factors which are determined as occurrence, severity and detection are used in the study. In this method, the number of the risk factors is not limited and can be increased if necessary. Team members working as engineers are selected from departments of production, planning and logistics. Relative weights of team members are determined according to their knowledge on production processes.

In the calculations, defuzzification and nominal average method are utilized to collect the group belief structures and transform them to general belief structures. In the grey theory application, comparative series are obtained in matrix form from the values which are taken from defuzzified belief matrix in fuzzy evidential approach. In this step, standard series are identified again in matrix form and then, differences between these two series are obtained to use in the calculation of grey relational coefficient. Finally, grey relational degrees are calculated for each failure modes by using grey relational coefficients and group weights of risk factors. The smaller the risk priority of failure modes are, the higher the grey relational degrees. After specific calculations of this method, six failure modes are prioritized and the defect of "unstable" should be considered as the most important and serious risk according to the analysis.

Relative weights of four team members are determined as $0.30,0.15,0.20$ and 0.35 , respectively.

Results of the assessment are used in (4) to obtain group belief structures. Group belief structures that are obtained from all risk factors and failure modes are shown in the Table III.

In the Table IV, defuzzified values are given that are obtained from fuzzy assessment degrees by using (7) where the values are taken from specific membership diagram.

After the defuzzification of fuzzy assessment degrees, these values are used to collect defuzzified group belief structures by using (7) and (8). These values exist in the Table $\mathrm{V}$ for all failure modes and risk factors. For example, defuzzified value is computed for occurence risk factor and fifth failure mode shown below.

$$
\begin{aligned}
& \left\{H_{44}(0.45), H_{15}(0.20), H_{45}(0.35)\right\}= \\
& (0.45 \times 0.708)+(0.20 \times 0.500)+(0.35 \times 0,741)
\end{aligned}
$$

Last calculation of fuzzy evidential approach is the calculation of weights that are used in grey theory method. Relative importance weights of all risk factors are collected by using (1). Values of weights are shown in the Table VI.

TABLE IV: DEFUZZIFIED CRISP NUMBERS OF FUZZY ASSESSMENT

\begin{tabular}{llllll}
\hline \multicolumn{7}{c}{ Dssess. } & Crisp & Assess. & Crisp & Asses. & Crisp \\
degree & number & degree & number & degree & number \\
\hline $\mathrm{H}_{11}$ & 0.130 & $\mathrm{H}_{22}$ & 0.292 & $\mathrm{H}_{34}$ & 0.567 \\
$\mathrm{H}_{12}$ & 0.259 & $\mathrm{H}_{23}$ & 0.433 & $\mathrm{H}_{35}$ & 0.606 \\
$\mathrm{H}_{13}$ & 0.394 & $\mathrm{H}_{24}$ & 0.500 & $\mathrm{H}_{44}$ & 0.708 \\
$\mathrm{H}_{14}$ & 0.459 & $\mathrm{H}_{25}$ & 0.541 & $\mathrm{H}_{45}$ & 0.741 \\
$\mathrm{H}_{15}$ & 0.500 & $\mathrm{H}_{33}$ & 0.500 & $\mathrm{H}_{55}$ & 0.870 \\
\hline \hline
\end{tabular}


For example, group weights for detection risk factor is computed by using numbers in fuzzy sets, weights of team members and factor weights.

$$
\begin{aligned}
& (0 \times 0.3)+(0.25 \times 0.15)+(0 \times 0.20)+(0.25 \times 0.35)=0.125 \\
& (0.25 \times 0.3)+(0.5 \times 0.15)+(0.25 \times 0.20)+(0.5 \times 0.35)=0.375 \\
& (0.5 \times 0.3)+(0.75 \times 0.15)+(0.5 \times 0.20)+(0.75 \times 0.35)=0.625
\end{aligned}
$$

TABLE III: DEFUZZIFIED CRISP NUMBERS OF FUZZY ASSESSMENT DEGREES

\begin{tabular}{|c|c|c|c|}
\hline $\begin{array}{l}\text { Failure } \\
\text { mode }\end{array}$ & Occurence & Severity & Detectability \\
\hline 1 & 0.818 & 0.456 & 0.527 \\
\hline 2 & 0.741 & 0.750 & 0.256 \\
\hline 3 & 0.440 & 0.471 & 0.443 \\
\hline 4 & 0.562 & 0.336 & 0.324 \\
\hline 5 & 0.678 & 0.259 & 0.321 \\
\hline 6 & 0.280 & 0.516 & 0.238 \\
\hline
\end{tabular}

\begin{tabular}{llll}
\hline \hline $\begin{array}{l}\text { Failure } \\
\text { modes }\end{array}$ & Probability & Severity & Detectability \\
\hline 1 & $\left\{\mathrm{H}_{55}(0.65), \mathrm{H}_{45}(0.15), \mathrm{H}_{44}(0.20)\right\}$ & $\left\{\mathrm{H}_{23}(0.655), \mathrm{H}_{33}(0.325), \mathrm{H}_{15}(0.02)\right\}$ & $\left\{\mathrm{H}_{22}(0.30), \mathrm{H}_{44}(0.15), \mathrm{H}_{35}(0.55)\right\}$ \\
2 & $\left\{\mathrm{H}_{55}(0.30), \mathrm{H}_{45}(0.395), \mathrm{H}_{44}(0.105), \mathrm{H}_{34}(0.20)\right\}$ & $\left\{\mathrm{H}_{44}(0.30), \mathrm{H}_{34}(0.15), \mathrm{H}_{45}(0.20)\right.$, & $\left\{\mathrm{H}_{12}(0.65), \mathrm{H}_{11}(0.15), \mathrm{H}_{22}(0.12), \quad \mathrm{H}_{23}(0.07)\right.$, \\
& & $\left.\mathrm{H}_{55}(0.35)\right\}$ & $\left\{\mathrm{H}_{15}(0.01)\right\}$ \\
3 & $\left\{\mathrm{H}_{25}(0.30), \mathrm{H}_{33}(0.15), \mathrm{H}_{15}(0.20), \mathrm{H}_{22}(0.35)\right\}$ & $\left\{\mathrm{H}_{34}(0.30), \mathrm{H}_{12}(0.15), \mathrm{H}_{23}(0.19), \mathrm{H}_{33}(0.29), \mathrm{H}_{23}(0.06), \mathrm{H}_{22}(0.35)\right\}$ & $\left\{\mathrm{H}_{12}(0.3), \mathrm{H}_{23}(0.15), \mathrm{H}_{22}(0.45), \mathrm{H}_{33}(0.1)\right\}$ \\
& & $\left.\mathrm{H}_{15}(0.01), \mathrm{H}_{33}(0.35)\right\}$ & $\left\{\mathrm{H}_{25}(0.30), \mathrm{H}_{11}(0.15), \mathrm{H}_{12}(0.20)\right.$, \\
& $\left\{\mathrm{H}_{45}(0.30), \mathrm{H}_{23}(0.15), \mathrm{H}_{15}(0.035), \mathrm{H}_{33}(0,515)\right\}$ & $\left.\mathrm{H}_{22}(0.35)\right\}$ & $\left\{\mathrm{H}_{23}(0.3), \mathrm{H}_{12}(0.485), \mathrm{H}_{22}(0.2), \mathrm{H}_{15}(0.015)\right\}$ \\
& & $\left\{\mathrm{H}_{12}(1.0)\right\}$ & $\left\{\mathrm{H}_{12}(0.65), \mathrm{H}_{22}(0.15), \mathrm{H}_{11}(0.2)\right\}$ \\
\hline
\end{tabular}

TABLE V: COLLECTED AND DEFUZZIFIED ASSESSMENT

TABLE VI: GROUP WEIGHTS OF RISK FACTORS

\begin{tabular}{llll}
\hline \hline & Occurence & Severity & Detection \\
\hline Group & $(0.488,0.73$, & $(0.538,0.788$, & $(0.125,0.375$, \\
weights & $0.913)$ & $0.95)$ & $0.625)$ \\
\multirow{2}{*}{ Weights } & 0.39 & 0.41 & 0.20 \\
\hline \hline
\end{tabular}

Steps of grey theory start with the calculation of group weights and determination of comparative series. Values in the Table $\mathrm{V}$ are used to generate comparative series that are obtained by using (8) and (10).

$$
X^{\prime}=X=\left[\begin{array}{lll}
0.818 & 0.456 & 0.527 \\
0.741 & 0.750 & 0.256 \\
0.440 & 0.471 & 0.443 \\
0.562 & 0.336 & 0.324 \\
0.678 & 0.259 & 0.321 \\
0.280 & 0.516 & 0.238
\end{array}\right]
$$

Standard series can be determined as "very low" which is the lowest value of linguistic term or zero. Standard series are determined as zero in this application.

$$
X_{0}=\left[\begin{array}{lll}
0 & 0 & 0 \\
0 & 0 & 0 \\
0 & 0 & 0 \\
0 & 0 & 0 \\
0 & 0 & 0 \\
0 & 0 & 0
\end{array}\right]
$$

After determination of comparative and standard series, difference of these series is formed.

$$
D_{0}=\left[\begin{array}{lll}
0.818 & 0.456 & 0.527 \\
0.741 & 0.750 & 0.256 \\
0.440 & 0.471 & 0.443 \\
0.562 & 0.336 & 0.324 \\
0.678 & 0.259 & 0.321 \\
0.280 & 0.516 & 0.238
\end{array}\right]
$$

Difference values of two series are used to compute the grey relation coefficient. For example, grey relational coefficients are computed for fourth failure mode below by using 13.

$$
\begin{aligned}
\gamma\left(X_{0}(l), X_{4}(l)\right) & =\frac{0.238+0.5 \times 0.818}{0.562+0.5 \times 0.818}=0.666 \\
\gamma\left(X_{0}(2), X_{4}(2)\right) & =\frac{0.238+0.5 \times \times 0.818}{0.336+0.5 \times \times 0.818}=0.868 \\
\gamma\left(X_{0}(3), X_{4}(3)\right) & =\frac{0.238+0.5 \times 0.818}{0.324+0.5 \times 0.818}=0.882
\end{aligned}
$$

Grey relation coefficient for all failure modes and risk factors are in the matrix below.

$$
\gamma\left(X_{0}(\mathrm{l}), X_{n}(\mathrm{l})\right)=\left[\begin{array}{lll}
0.527 & 0.748 & 0.691 \\
0.563 & 0.558 & 0.973 \\
0.762 & 0.735 & 0.759 \\
0.666 & 0.868 & 0.882 \\
0.595 & 0.968 & 0.886 \\
0.939 & 0.699 & 1.000
\end{array}\right]
$$

Lastly, degrees of relation are computed in the grey theory and risks are prioritized according to results. Values are found from (14). For example, degree of relation for the fifth failure mode is computed below.

$$
\begin{aligned}
& \Gamma\left(X_{m}, X_{n}\right)[(0.595 \times 0.39)+(0.968 \times 0.41)+(0.886 \times 0.2)] \\
= & 0.806
\end{aligned}
$$


Degrees of relation for the six failure modes are determined as $0.650,0.643,0.750,0.792,0.806$ and 0.853 respectively. Considering these values, the lowest value is accepted the highest risk. Six failure modes are prioritized as $H T_{2}>H T_{1}>H T_{3}>H T_{4}>H T_{5}>H T_{6}$ accordingly.

\section{CONCLUSION}

FMEA is an important tool for prioritization of risks in many industries. It is getting difficult to prioritize the failures with traditional FMEA in more complicated, fuzzy and detailed world. The method proposed by Liu, Bian, Lin and $\mathrm{Xu}$ provides possibility to team members to combine their uncertain and various ideas for prioritization of risks that corresponds more practical and faster working and more accurate results [10]. That's why, this method will be very useful certainly in the production part of the automotive industry if it can be applied and become widespread.

Advantages and better sides of FMEA using fuzzy evidential approach and grey theory compared to traditional FMEA are stated in this study. An application is conducted in a truck production company of Turkey. So, it is clear that automotive industry includes very difficult, detailed and complicated processes that consist of many risks. Therefore, it is very important to determine the risks faster and certainly without any necessity to turn back. There is no doubt that fuzzy evidential approach and grey theory will be useful in the automotive sector especially in production section.

\section{REFERENCES}

[1] Automotive Industry Report Republic of Turkey Ministry of Science Industry and Technology, Ankara, 2012

[2] Automotive Manufacturers Association Report, Istanbul, 2011.

[3] Turkey Automotive Industry Report Deloitte, Istanbul, 2009.

[4] T. Aven, Foundations of Risk Analysis, John Wiley \& Sons, West Sussex, 2003, p.15.

[5] R. Kenett and Y. Raanan, Operational Risk Management: A Practical Approach to Intelligent Data Analysis, John Wiley \& Sons, 2011, p. 45 .

[6] Operational Risk, Basel Committee on Banking Supervision, 2001.
[7] Operational Risk Management, Marine Corps Institute, 2002.

[8] J. Hallikas, I. Karvonen, U. Pulkkinen, V. M. Virolainen, and M. Tuominen, "Risk management processes in suppliernet works," International Journal of Production Economics, vol. 90, no. 1, pp. 4758, 2004.

[9] H. Liu, L. Liu, and N. Liu, "Risk evaluation approaches in failure mode and effects analysis: A literature review," Expert Systems with Applications, vol. 40, no. 2, pp. 828-838, 2013.

[10] H. Liu, L. Liu, Q. Bian, Q. Lin, N. Dong, and P. Xu, "Failure mode and effects analysis using fuzzy evidential reasoning approach and grey theory," Expert Systems with Applications. vol. 38, pp. 4403-4415, 2011.

[11] J. Yang and D. Xu, "On the evidential reasoning algorithm for multiple attribute decision analysis under uncertainty," IEEE Transactions on Systems. Man and Cybernetics - Part A: Systems and Humans, vol. 32, no. 3, pp. 289-304, 2002

[12] K. C. Shih, K. W. Wu, and U. P. Huang, Information of Grey Relation, Taiwan: Chuan-Hua Co. Ltd., 1996.

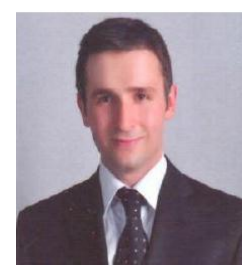

Mehmet Turgut was born in 1986. He graduated from the Chemical Engineering Department of Istanbul Technical University (ITU) in 2010. He got his MSc degree in industrial engineering from ITU in 2012. He has worked in Mercedes Benz Turk A.S. since 2011. His current research interests include risk management and logistics.

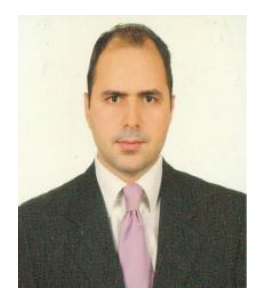

Alp Ustundag was born in 1977. He graduated from the Industrial Engineering Department of Istanbul Technical University (ITU) in 2000. He got his MBA degree from Bogazici University in 2002 and his doctoral degree from ITU in 2008. He conducted research studies at the Logistics Department of Dortmund University, Germany in 2007. He became an associate professor in 2011 in ITU. He is currently the head of RFID Research and Test Lab in Istanbul Technical University and also a lecturer at the Industrial Engineering Department of ITU.

$\mathrm{He}$ has conducted a lot of research and consulting projects in reengineering, logistics and supply chain management for major Turkish companies. His current research interests include RFID, supply chain and logistics management, innovation and technology management, risk management, IT/IS systems, soft computing and optimization. He has published many papers in international journals and presented various studies at national and international conferences. 